\title{
Heterogeneity in the prognosis of major depression: from the common cold to a highly debilitating and recurrent illness
}

\author{
L. Lorenzo-Luaces \\ Department of Psychology, University of Pennsylvania, Philadelphia, PA 19104, USA
}

\begin{abstract}
Two different and seemingly competing views on the diagnosis of major depressive disorder (MDD) exist. The first is that the diagnosis conflates adaptive sadness reactions with pathological states of depressed mood and that MDD is overdiagnosed and overtreated. The second is that MDD is an underdiagnosed and undertreated disorder, and one that is best characterised by a severe, chronic, recurrent or treatment-resistant course. Existing research suggests that both views are valid and merit being integrated. Anywhere from 30 to 50\% of individuals will meet criteria for MDD at some point in their life. About half of these episodes are of brief duration and unlikely to recur. However, a remaining half is either chronic or recurrent. Data on the outpatient diagnosis of depression support the view that depression is simultaneously underdiagnosed and undertreated as well as overdiagnosed and overtreated. About one-third of the patients who meet criteria for MDD and receive placebos experience clinically significant and long-lasting improvement. Many other patients, however, are unresponsive to one or multiple active treatments. Thus, the diagnosis of MDD likely applies to individuals who are experiencing either normal periods of sadness or single-episode afflictions that are mild, unlikely to recur, and are placebo responsive, as well as to individuals with more severe clinical profiles. More research is needed that can help ascertain what contextual or biopsychological variables help distinguish between individuals who may be experiencing adaptive states of negative affect and those who experience severe, chronic, recurrent or treatment-resistant depressions.
\end{abstract}

Received 5 May 2015; Accepted 27 May 2015; First published online 17 June 2015

Key words: Diagnosis, major depressive disorder, public health, sadness.

Depressive disorders are currently estimated to be the 11th leading cause of disability worldwide (Murray et al. 2013). One of most commonly cited estimates of the prevalence of major depressive disorder (MDD) is the $16.2 \%$ figure reported by Kessler et al. (2003). Taken at face value, this estimate is alarming. In effect, it has been met with some skepticism as it suggests a very high prevalence of MDD (Parker, 2007a). However, Angst et al. (2015) recently published data that suggest that this may be a conservative estimate. These researchers published data from a 30-year prospective study in which individuals were interviewed at least seven different times. In that sample, 32.5\% of individuals met criteria for MDD at some point during the assessment period. Their findings suggest that the prevalence of MDD is underestimated by epidemiology studies that rely on retrospective assessment of lifetime disorder status. As noted by the authors,

Address for correspondence: L. Lorenzo-Luaces, Department of Psychology, University of Pennsylvania, 3720 Walnut Street D 20, Philadelphia, PA 19104, USA.

(Email: lorenzl@sas.upenn.edu) such a high cumulative lifetime prevalence from prospective assessments of MDD is not an empirical anomaly. For example, using data from a small sample of Australian teachers, Wilhelm et al. (2006) reported a $42 \%$ cumulative lifetime prevalence of MDD over a 25-year period (Wilhelm et al. 2006). In the Dunedin Multidisciplinary Health and Development Study in New Zealand, about $40 \%$ of the sample met criteria for MDD at some point in their life (Moffitt et al. 2010). Similar findings emerged from the Oregon Adolescent Depression Project in the United States (USA). Half of that sample (51\%) met criteria for MDD at some point before the age of 30 (Rohde et al. 2013). Thus, if there should be any skepticism regarding the estimates of Kessler et al. (2003), it is that they appear to be underestimates! Because even the prospective studies only report prevalence data up to the point of the interview, the lifetime risk of MDD must be even higher than what has been reported.

What is to be made of these alarmingly high prevalence rates? On the one hand, it is possible that MDD is an even greater public health concern than is generally appreciated, as the prospectively assessed lifetime prevalence of MDD is 2-3 times greater than the 
retrospectively assessed prevalence (Moffitt et al. 2010). If MDD such a deleterious condition, however, it is somewhat puzzling that most individuals fail to report depressive episodes. This difference between retrospective and prospective assessments is not present in inquiries of physical health disorders such as diabetes, hypertension or arthritis (Takayanagi et al. 2014b). Demographic features like old age have been associated to failure to recall MDD status (Takayanagi et al. 2014b). However, depressive episodes have been described as 'scarring', with the potential to change the individual's personality. Thus it seems unlikely that a poor memory accounts for why most individuals fail to recall meeting MDD criteria.

A possible account for the discrepancy between prospectively-assessed and retrospectively assessed lifetime prevalence rates is that many individuals experience depression as one of many 'homeostatic responses to internal or external stimuli that do not represent true psychopathologic disorders' (Regier et al. 1998, p. 114), and as such do not report them as part of their psychiatric history. Lending support to this hypothesis, individuals often fail to report depressive symptoms that they perceive as associated to stress or medical conditions (Eaton et al. 2000). The idea that the diagnosis of MDD conflates individuals who are very ill with those who might be experiencing normal, and perhaps even adaptive responses, has been raised as a major concern (Horwitz \& Wakefield, 2007; Parker, 2007a; Shorter, 2013). A common retort to these arguments is that whereas MDD might seem episodic, common, adaptive and overrecognised, it is in fact chronic, recurrent, maldaptive and underrecognised (Hickie, 2007). The existing data, however, support both views.

\section{Duration and recurrence}

According to the DSM 5, one of the features of MDD that makes it pathological and distinct from normal states of negative affect is its prolonged duration (American Psychiatric Association, 2013). Perhaps as a corollary, depressive episodes are believed to be long-lasting. For example, Joiner (2000) cites Shapiro \& Keller (1981) in reporting that the median duration of major depressive episodes (MDEs) is 8 months. It is also widely believed that MDD is highly recurrent such that individuals who recover from an episode are still considered to be at a very high risk for future episodes. For example, in a paper preceded by the quote '[s]ingle episodes are extremely rare if the period of observation is significantly extended', Mueller et al. (1999) reported that $85 \%$ of individuals in a sample who recovered from an index episode had experienced a recurrence by the end of a 15-year follow-up. Both of these estimates come from analyses of the NIMH Collaborative Study of the Psychobiology of Depression and are widely cited because studies with such long follow-ups are few and far between. Taken together, these estimates suggest that MDD can be a disorder of a prolonged and highly recurring course.

However, as has been noted by Eaton et al. (1997, 2008), estimates of the chronicity and recurrence of MDD that come from clinical samples do not generalise to most patients who meet MDD criteria. Data from studies in naturalistic European and North American samples suggest that about half of individuals recover from a MDE within a period of 3 months and most (about 75\%) experience recovery in a 3-6-month period (Eaton et al. 1997, 2008; Spijker et al. 2002). Thus, longlasting depressive episodes appear to be quite rare (see also Patten et al. 2010). Although recurrence rates from long-term follow-ups of population-based studies are lacking, the few studies there are suggest that single-episode MDD is more common than recurrent MDD. In one of the longest follow-up studies to date, Eaton et al. (2008) reported that, in a 23-year period, about $35 \%$ of individuals experienced recurring depression and $15 \%$ experienced an unremitting course. Thus, half of the individuals recovered from their episode within 3-6 months and did not go on to have another episode. Similar findings were produced by a 30 39-year follow-up of a European cohort (Mattisson et al. 2007), suggesting that significantly extending the observation does not lead to substantially higher rates of recurrence (see also Steinert et al. 2014).

\section{Placebo responses}

Another piece of data that bolsters the claim that the diagnosis of MDD can apply to individuals with a wide range of clinical profiles is the diversity and multiplicity of treatments available for depression. On the one hand, there are treatments for intractable cases which include electroconvulsive therapy and transcranial magnetic stimulation. These treatments share the features of acting directly on the brain and requiring extensive medical intervention. At the other extreme there are efficacious treatments for MDD, which are not very intensive. These include unguided self-help (Cuijpers et al. 2010) and physical exercise (Babyak et al. 2000).

The most widely recommended and researched treatments for MDD, however, are antidepressants and psychotherapy. Reviews of the literature suggest that about $40-60 \%$ of individuals respond to antidepressants or psychotherapy (Walsh et al. 2002; Cuijpers et al. 2014). This leaves a sizeable proportion of patients who are 
treatment non-responders. However, it is also noteworthy that around one-third of the patients who are randomised to placebo controls experience clinically significant improvement (Walsh et al. 2002; Cuijpers et al. 2014). Meta-analytic reviews and aggregation of data from multiple studies suggest that antidepressants are only superior to placebos for individuals with very severe forms of depression (Khan et al. 2002; Kirsch et al. 2008; Fournier et al. 2010; Barbui et al. 2011) and analogous findings have emerged in regards to the efficacy of psychotherapy (Driessen et al. 2010). Taken together, these findings suggest that the active treatments for depression are only superior to presumably inert placebos and control conditions for the minority of individuals who have severe or very severe MDD. Caution must be taken when considering severity in relation to treatment response, given that other variables such as chronicity and recurrence also predict treatment response (Hollon et al. 2014). However, there is evidence that a high placebo response rate in depression trials is present even in patients with more complex clinical pictures (Brunoni et al. 2009). Moreover, the placebo response seems to be increasing over time (Walsh et al. 2002), a finding that has been replicated and seems accounted for, statistically, by an increase in the heterogeneity of patient samples (Rief et al. 2009). It is not difficult to piece together the increase in placebo response with the arguments about the MDD criteria becoming overly inclusive.

Although the placebo response in MDD has often been attributed to non-specific relief that is not thought to endure, most patients who respond to placebos actually stay well (Khan et al. 2008). Additionally, studies on the long-term course of untreated depression suggest that the outcomes of individuals who do not receive treatment for depression are comparable with the long-term outcomes of individuals who are treated with antidepressants (Hughes \& Cohen, 2009), again a somewhat puzzling findings if we assume most cases of MDD to be either severe, chronic, recurrent or treatment-resistant.

Patients in clinical trials are (self-)selected on the basis on severity and perceived need for treatment. That even these patients experience a substantial placebo response is consistent with the view that some individuals who meet MDD criteria may better be understood as experiencing normal reactions to life stressors that are self-ameliorating.

\section{Diagnosing and treating depression}

Depression is very clearly a significant public health concern. The amount of money that is spent on, as well as is lost to, symptoms of depression clearly attests to this. Highly chronic, frequently recurrent and treatment-resistant depressions are all real phenomena. However, the extremely high prevalence rates that have been reported in prospective studies 'strain credulity' and 'undermine the [diagnostic] model's credibility' (Parker, 2008, p. 842). The evidence reviewed suggests that $35-50 \%$ of people will meet the criteria for MDD at some point in a 20-30-year period (Wilhelm et al. 2006; Moffitt et al. 2010; Rohde et al. 2013; Angst et al. 2015). It would not be unreasonable to conclude from these data that if a population of individuals were followed indefinitely and assessed more frequently, most would meet criteria for MDD at some point in their life. Most of these episodes would be brief (Eaton et al. 1997, 2008; Spijker et al. 2002; Patten et al. 2010) and many individuals would not experience another episode (Eaton et al. 1997, 2008; Mattisson et al. 2007; Steinert et al. 2014). Most would not seek treatment, which is just as well because many would probably not receive treatment it even if they did seek it. Of those who did seek treatment and were able to obtain it, a sizeable amount would have experienced about the same clinically significant and longlasting improvement from a sugar pill. This state of affairs is almost impossible to reconcile with a somewhat alarmist view that MDD is best, and perhaps only, understood as being underdiagnosed or underdetected.

Although it may not be appropriate to say that depression is underdiagnosed, it is also not appropriate to simply say that MDD is overdiagnosed. A Goldilocks retort that depression is appropriately diagnosed is obviously not a fair characterisation either. Instead, it seems to be the case that depression is both over- and underdiagnosed. For example, Mitchell et al. (2009) reviewed 41 studies on the detection of depression in primary care and found that general practitioners (GPs) only correctly diagnosed depression in about half of patients who met the criteria. They failed to identify depression mostly in patients who had milder symptoms. However, these authors also found that the most common mistake GPs made was diagnosing depression in patients who did not meet the criteria. Thus, at least in primary care, it appears that depression is both over- and underrecognised. These findings should not be dismissed under the assumption that different findings would be obtained in more specialised settings. The diagnostic practices in primary care are very telling of the state of outpatient depression treatment because most treatment for MDD, namely prescription of antidepressants, occurs in the context of primary care (Wun et al. 2011).

In the USA, there are clear data evidencing that patients are increasingly being prescribed 
antidepressants without receiving a diagnosis of MDD from their physicians, a practice that is more common among GPs than psychiatrist (Mojtabai \& Olfson, 2010). It is not just that patients meet MDD criteria but are not diagnosed as such by their GPs. Rather they do not and have never met MDD criteria. For example, Mojtabai \& Olfson (2008) reported that, in the USA, only $43 \%$ of those currently treated with antidepressants by a GP met the 12-month criteria for a mood or anxiety disorder. In one nationally representative sample, one out of four individuals currently on an antidepressant had never even met the retrospectively assessed criteria for a mood or anxiety disorder at any point in their life (Pagura et al. 2011). In a study that used prospective assessments, about $70 \%$ of individuals who took antidepressants never met criteria for MDD and around 40\% never met criteria for any of the so-called 'common' mood or anxiety disorders assessed (Takayanagi et al. 2014a). Antidepressants are prescribed in the absence of psychiatric diagnoses for patients who present with subthreshold symptoms as well as those with generalised psychosocial issues or non-specific somatic complaints (Salmon et al. 2006; Pagura et al. 2011). Discussing these studies, Pagura et al. (2011) concluded that 'antidepressant use is becoming concentrated among people with less severe and poorly defined mental health conditions' (p. 1441).

\section{Future recommendations}

Attention has been called to the fact that most research on depression has focused on its chronic and recurrent forms (Monroe \& Harkness, 2011, 2012). A focus on chronic and recurrent depressions has led to an inability to identify what it is exactly that keeps cases from having a more benign course. In addition to research focusing on less chronic and recurrent depressions, more research is needed to understand milder cases, as well at those that seem to be placebo-responsive.

Depression is heterogeneous both in its symptomatic presentation and its prognosis. It is unsurprising then that whereas some prominent commentators have referred to it as the 'common cold of psychopathology' (Seligman, 1975, p. 75), others have emphasised its 'severe, relapsing, and chronic' nature (Judd et al. 2000, p. 1501). Although the current diagnostic criteria for MDD have been extensively criticised, discontent appears to be at an all-time high (Greenberg, 2013; Frances, 2014). In this context, in the USA, the National Institute of Mental Health has called for a new empirically derived and biologically based classification system informed by their Research Domain Criteria. Their priorities include a characterisation of the neural bases of depression and the identification of vulnerability genes. Identifying vulnerability genes is an important task. However, given the heterogeneity of depressive presentations, knowing that someone is at risk for MDD can be of limited value, especially if around half of the population is at risk. What are needed are attempts to predict more clinically relevant variables such as severity, chronicity, recurrence and treatment response. Indeed, limited evidence suggests that whereas the overall heritability of MDD is relatively modest, its more severe and recurrent forms are more highly heritable (Lyons et al. 1998; Sullivan et al. 2000).

A characterisation of neural functioning in patients with depression is also likely to be a major contribution to our understanding of mood pathology. However, the pattern of neural activation seen in MDD patients often overlaps with the neural patterns that healthy controls exhibit after sad mood inductions (Andrews \& Thomson, 2009). Thus, the more informative characterisations of depression are likely to be those that differentiate patients who are depressed from those who are experiencing transient states of sadness. Along these lines, Wakefield et al. have brought attention to the need to focus on symptoms of depression that are not mere indicators of distress but are instead pathosuggestive (e.g., Wakefield et al. 2007; Wakefield \& Schmitz, 2013; Wakefield \& Schmitz, 2014). A prolonged duration, thoughts of worthlessness, psychomotor retardation and psychoticism have emerged as useful variables in this regard. Parker (2007b) has proposed a model of depression where psychomotor disturbances and psychoticism play a key role as variables that distinguish pathological affective states from more generalised distress. Malhi et al. (2005) suggest a tiered model of depression as involving an additive dysfunction of monoamines, starting with serotonergic disturbances for more generalised states of negative affect and including noradrenergic and dopaminergic disturbances for psychomotor retardation and psychoticism, respectively. Examinations of these and other theories of specific pathologies are likely to be more effective than general contrasts between healthy individuals and those who meet criteria for MDD.

Depression can be conceptualised as involving the hyperactivation of negative emotional systems, especially those involved in reactions to losses, and diminished activation of positive emotional systems, especially those involved in reward processing. However, the determination of whether an emotional reaction is excessively or deficient relies on a consideration of the context in which it occurs (Horwitz \& Wakefield, 2007). Emerging research suggests that, like the symptoms of depression, the context in which depressive symptoms occur can also be reliably evaluated (Parker et al. 2012). Prospective studies exploring the association between the context, 
prognosis and pathophysiology of depressive states are needed. Even if these studies cannot provide conclusive evidence regarding the demarcation between pathological states of depression and adaptive states of sadness, they can shed light on the heterogeneity of depressive presentations.

\section{Financial support}

This research received no specific grant from any funding agency, commercial or not-for-profit sectors.

\section{Conflict of interest}

None.

\section{References}

American Psychiatric Association (2013). Diagnostic and Statistical Manual of Mental Disorders, 5th edn. American Psychiatric Association: Washington, DC.

Andrews PW, Thomson JA Jr (2009). The bright side of being blue: depression as an adaptation for analyzing complex problems. Psychological Review 116, 620-654.

Angst J, Paksarian D, Cui L, Merikangas KR, Hengartner MP, Ajdacic-Gross V, Rossler W (2015). The epidemiology of common mental disorders from age 20 to 50: results from the prospective Zurich cohort study. Epidemiology and Psychiatric Sciences, advanced online publication, doi: 10.1017/S204579601500027X.

Babyak M, Blumenthal JA, Herman S, Khatri P, Doraiswamy M, Moore K, Craighead WE, Baldewicz TT, Krishnan KR (2000). Exercise treatment for major depression: maintenance of therapeutic benefit at 10 months. Psychosomatic Medicine 62, 633-638.

Barbui C, Cipriani A, Patel V, Ayuso-Mateos JL, van Ommeren M (2011). Efficacy of antidepressants and benzodiazepines in minor depression: systematic review and meta-analysis. The British Journal of Psychiatry 198, $11-16$.

Brunoni AR, Lopes M, Kaptchuk TJ, Fregni F (2009). Placebo response of non-pharmacological and pharmacological trials in major depression: a systematic review and meta-analysis. PLoS ONE 4, e4824.

Cuijpers P, Donker T, van Straten A, Li J, Andersson G (2010). Is guided self-help as effective as face-to-face psychotherapy for depression and anxiety disorders? A systematic review and meta-analysis of comparative outcome studies. Psychological Medicine 40, 1943-1957.

Cuijpers P, Karyotaki E, Weitz E, Andersson G, Hollon SD, van Straten A (2014). The effects of psychotherapies for major depression in adults on remission, recovery and improvement: a meta-analysis. Journal of Affective Disorders 159, 118-126.
Driessen E, Cuijpers P, Hollon SD, Dekker JJ (2010). Does pretreatment severity moderate the efficacy of psychological treatment of adult outpatient depression? A meta-analysis. Journal of Consulting and Clinical Psychology 78, 668-680.

Eaton WW, Anthony JC, Gallo J, Cai G, Tien A, Romanoski A, Lyketsos C, Chen L-S (1997). Natural history of diagnostic interview schedule DSM-IV major depression: the Baltimore epidemiologic catchment area follow-up. Archives of General Psychiatry 54, 993-999.

Eaton WW, Neufeld K, Chen L-S, Cai G (2000). A comparison of self-report and clinical diagnostic interviews for depression: diagnostic interview schedule and schedules for clinical assessment in neuropsychiatry in the Baltimore Epidemiologic Catchment Area follow-up. Archives of General Psychiatry 57, 217-222.

Eaton WW, Shao H, Nestadt G, Lee BH, Bienvenu OJ, Zandi P (2008). Population-based study of first onset and chronicity in major depressive disorder. Archives of General Psychiatry 65, 513-520.

Fournier JC, DeRubeis RJ, Hollon SD, Dimidjian S, Amsterdam JD, Shelton RC, Fawcett J (2010). Antidepressant drug effects and depression severity. The Journal of the American Medical Association 303, 47-53.

Frances AJ (2014). Saving Normal: An Insider's Revolt against Out-of-Control Psychiatric Diagnosis, DSM-5, Big Pharma, and the Medicalization of Ordinary Life. William Morrow Paperbacks: New York.

Greenberg G (2013). The Book of Woe: The DSM and the Unmaking of Psychiatry. Penguin Books: London.

Hickie I (2007). Head to head: is depression overdiagnosed? No. British Medical Journal 335, 329.

Hollon SD, DeRubeis RJ, Fawcett J, Amsterdam JD, Shelton RC, Zajecka J, Young PR, Gallop R (2014). Effect of cognitive therapy with antidepressant medications vs antidepressants alone on the rate of recovery in major depressive disorder: a randomized clinical trial. JAMA Psychiatry 71, 1157-1164.

Horwitz AV, Wakefield JC (2007). The Loss of Sadness: How Psychiatry Transformed Normal Sorrow into Depressive Disorder. Oxford University Press: New York.

Hughes S, Cohen D (2009). A systematic review of long-term studies of drug treated and non-drug treated depression. Journal of Affective Disorders 118, 9-18.

Joiner TE (2000). Depression's vicious scree: self-propagating and erosive processes in depression chronicity. Clinical Psychology: Science and Practice 7, 203-218.

Judd LL, Paulus MJ, Schettler PJ, Akiskal HS, Endicott J, Leon AC, Maser JD, Mueller T, Solomon DA, Keller MB (2000). Does incomplete recovery from first lifetime major depressive episode herald a chronic course of illness? American Journal of Psychiatry 157, 1501-1504.

Kessler RC, Berglund P, Demler O, Jin R, Koretz D, Merikangas KR, Rush AJ, Walters EE, Wang PS (2003). The epidemiology of major depressive disorder: results from the National Comorbidity Survey Replication (NCS-R). The Journal of the American Medical Association 289, 3095-3105.

Khan A, Leventhal RM, Khan SR, Brown WA (2002). Severity of depression and response to antidepressants and 
placebo: an analysis of the food and drug administration database. Journal of Clinical Psychopharmacology 22, 40-45.

Khan A, Redding N, Brown WA (2008). The persistence of the placebo response in antidepressant clinical trials. Journal of Psychiatric Research 42, 791-796.

Kirsch I, Deacon BJ, Huedo-Medina TB, Scoboria A, Moore TJ, Johnson BT (2008). Initial severity and antidepressant benefits: a meta-analysis of data submitted to the food and drug administration. PLoS Medicine 5, e45.

Lyons MJ, Eisen SA, Goldberg J, True W, Lin N, Meyer JM, Toomey R, Faraone SV, Merla-Ramos M, Tsuang MT (1998). A registry-based twin study of depression in men. Archives of General Psychiatry 55, 468-472.

Malhi GS, Parker G, Greenwood J (2005). Structural and functional models of depression: from sub-types to substrates. Acta Psychiatrica Scandinavica 111, 94-105.

Mattisson C, Bogren M, Horstmann V, Munk-Jörgensen P, Nettelbladt P (2007). The long-term course of depressive disorders in the Lundby Study. Psychological Medicine 37, 883-891.

Mitchell AJ, Vaze A, Rao S (2009). Clinical diagnosis of depression in primary care: a meta-analysis. The Lancet $\mathbf{3 7 4}$, 609-619.

Moffitt TE, Caspi A, Taylor A, Kokaua J, Milne BJ, Polanczyk G, Poulton R (2010). How common are common mental disorders? Evidence that lifetime prevalence rates are doubled by prospective versus retrospective ascertainment. Psychological Medicine 40, 899-909.

Mojtabai R, Olfson M (2008). National patterns in antidepressant treatment by psychiatrists and general medical providers: results from the National Comorbidity Survey Replication. Journal of Clinical Psychiatry 69, 1064-1074.

Mojtabai R, Olfson M (2010). Proportion of antidepressants prescribed without a psychiatric diagnosis is growing. Health Affairs 30, 1434-1442.

Monroe SM, Harkness KL (2011). Recurrence in major depression: a conceptual analysis. Psychological Review 118, 655-674.

Monroe SM, Harkness KL (2012). Is depression a chronic mental illness? Psychological Medicine 42, 899-902.

Mueller TI, Leon AC, Keller MB, Solomon DA, Endicott J, Coryell W, Warsaw M, Maser JD (1999). Recurrence after recovery from major depressive disorder during 15 years of observational follow-up. American Journal of Psychiatry 156, 1000-1006.

Murray CJ, Vos T, Lozano R, Naghavi M, Flaxman AD, Michaud C, Ezzati M, Shibuya K, Salomon JA, Abdalla S, Aboyans V, Abraham J, Ackerman I, Aggarwal R, Ahn SY, Ali MK, AlMazroa MA, Alvarado M, Anderson HR, Anderson LM (2013). Disability-adjusted life years (DALYs) for 291 diseases and injuries in 21 regions, 1990-2010: a systematic analysis for the Global Burden of Disease Study 2010. The Lancet 380, 2197-2223.

Pagura J, Katz LY, Mojtabai R, Druss BG, Cox B, Sareen J (2011). Antidepressant use in the absence of common mental disorders in the general population. Journal of Clinical Psychiatry 72, 494-501.
Parker G (2007a). Is depression overdiagnosed? Yes. British Medical Journal 335, 328-328.

Parker G (2007b). Defining melancholia: the primacy of psychomotor disturbance. Acta Psychiatrica Scandinavica 115, 21-30.

Parker G (2008). How should mood disorders be modelled? Australian and New Zealand Journal of Psychiatry 42, 841-850.

Parker G, Fletcher K, Hadzi-Pavlovic D (2012). Is context everything to the definition of clinical depression? A test of the Horwitz and Wakefield postulate. Journal of Affective Disorders 136, 1034-1038.

Patten SB, Wang JL, Williams J, Lavorato DH, Khaled SM, Bulloch A (2010). Predictors of the longitudinal course of major depression in a Canadian population sample. Canadian Journal of Psychiatry 55, 669-676.

Regier DA, Kaelber CT, Rae DS, Farmer ME, Knauper B, Kessler RC, Norquist GS (1998). Limitations of diagnostic criteria and assessment instruments for mental disorders: implications for research and policy. Archives of General Psychiatry 55, 109-115.

Rief W, Nestoriuc Y, Weiss S, Welzel E, Barsky AJ, Hofmann SG (2009). Meta-analysis of the placebo response in antidepressant trials. Journal of Affective Disorders 118, 1-8.

Rohde P, Lewinsohn PM, Klein DN, Seeley JR, Gau JM (2013). Key characteristics of major depressive disorder occurring in childhood, adolescence, emerging adulthood, and adulthood. Clinical Psychological Science 1, 41-53.

Salmon P, Humphris GM, Ring A, Davies JC, Dowrick CF (2006). Why do primary care physicians propose medical care to patients with medically unexplained symptoms? A new method of sequence analysis to test theories of patient pressure. Psychosomatic Medicine 68, 570-577.

Seligman ME (1975). Helplessness: On Depression, Development, and Death, Vol. 1. WH Freeman: San Francisco.

Shapiro RW, Keller MB (1981). Initial 6-month follow-up of patients with major depressive disorder: a preliminary report from the NIMH collaborative study of the psychobiology of depression. Journal of Affective Disorders 3, 205-220.

Shorter E (2013). How Everyone Became Depressed: The Rise and Fall of the Nervous Breakdown. Oxford University Press: New York.

Spijker J, de Graaf R, Bijl RV, Beekman ATF, Ormal J, Nolen WA (2002). Duration of major depressive episodes in the general population: results from The Netherlands Mental Health Survey and Incidence Study (NEMESIS). The British Journal of Psychiatry 181, 208-213.

Steinert C, Hofmann M, Kruse J, Leichsenring F (2014). The prospective long-term course of adult depression in general practice and the community. A systematic literature review. Journal of Affective Disorders 152, 65-75.

Sullivan PF, Neale MC, Kendler KS (2000). Genetic epidemiology of major depression: review and meta-analysis. American Journal of Psychiatry 157, 1552-1562.

Takayanagi Y, Spira A, Bienvenu O, Hock R, Carras M, Eaton W, Mojtabai R (2014a). Antidepressant use and lifetime history of mental disorders in a community sample: results from the Baltimore Epidemiologic Catchment Area Study. The Journal of Clinical Psychiatry 76, 40-44. 
Takayanagi Y, Spira AP, Roth KB, Gallo JJ, Eaton WW, Mojtabai R (2014b). Accuracy of reports of lifetime mental and physical disorders: results from the Baltimore epidemiological catchment area study. JAMA Psychiatry 71, 273-280.

Wakefield JC, Schmitz MF (2013). When does depression become a disorder? Using recurrence rates to evaluate the validity of proposed changes in major depression diagnostic thresholds. World Psychiatry 12, 44-52.

Wakefield JC, Schmitz MF (2014). Predictive validation of single-episode uncomplicated depression as a benign subtype of unipolar major depression. Acta Psychiatrica Scandinavica 129, 445-457.

Wakefield JC, Schmitz MF, First MB, Horwitz AV (2007). Extending the bereavement exclusion for major depression to other losses: evidence from the National Comorbidity Survey. Archives of General Psychiatry 64, 433-440.

Walsh BT, Seidman SN, Sysko R, Gould M (2002). Placebo response in studies of major depression: variable, substantial, and growing. The Journal of the American Medical Association 287, 1840-1847.

Wilhelm K, Mitchell PB, Niven H, Finch A, Wedgwood L, Scimone A, Blair IP, Parker G, Schofield PR (2006).

Life events, first depression onset and the serotonin transporter gene. The British Journal of Psychiatry 188, 210-215.

Wun YT, Lamb TP, Goldberg D, Lam KF, Donald Li KT, Yip KC (2011). Reasons for preferring a primary care physician for care if depressed. Family Medicine 43, 344-350. 